\title{
Diabetes control and the influence of family functioning
}

\author{
Alexandra Louise Whitehead ${ }^{1}$, Margaret Dimmock ${ }^{2}$ and Maurice Place ${ }^{3 *}$ \\ *Correspondence: maurice.place@northumbria.ac.uk \\ ${ }^{1}$ CDClinPsy, Clinical Psychologist, Forensic Learning Disability Service and Adult Autism Service, Sniperley House, Lanchester Road \\ Hospital, Durham, DH1 5RD, UK. \\ ${ }^{2}$ Family Therapist, Hartlepool Child \& Adolescent Mental Health Service, Dover House, Lynn Street, Hartlepool, TS24 7JZ, UK. \\ ${ }^{3}$ FRCPsych, Child \& Family Psychiatrist, School of Health and Life Sciences, Northumbria University, Coach Lane Campus, Newcastle \\ upon Tyne, NE7 7XA, UK.
}

\begin{abstract}
Background: The link between glycaemic control of type 1 diabetes and family functioning is complex, with the existing literature largely focussing upon the association between clear patterns of disturbances in family functioning and suboptimal diabetic control. The more subtle changes to family function that might influence the degree of successful management of a child's diabetes have been less well studied.

Methods: This study sought to explore whether suboptimal glycaemic control was associated with variations in family functioning that might not in themselves prompt concern in routine clinic review. The project focussed on families attending for routine follow-up in specialist paediatric diabetes clinics in the North East of England. Mother and child participants provided demographic information and completed the Family Adaptation and Cohesion Evaluation Scale (FACES IV), and the quality of their glycaemic control was assessed using the mean HbAlc value for each child over the last year. Families with clear emotional or family difficulties, or where the level of control was causing clear concern were excluded (as were families where there was major physical or a member with significant learning disabilities). The sample was divided into two groups; families whose children were in optimal glycaemic control of their diabetes, and families where the glycaemic control was suboptimal.

Results: Whatever the degree of control, nearly all the mothers and index children reported functioning within the balanced range. The mothers of children with optimal glycaemic control reported their family to be more cohesive and expressed greater satisfaction with family life than mothers whose child's glycaemic control was suboptimal. The children with suboptimal diabetic control also tended to view their family life as more chaotic.

Discussion: Despite the challenges most families cope reasonably well with the issues that managing type 1 diabetes in a child bring. However suboptimal control tends to be associated with some unhelpful family issues, and the implications for intervention are discussed.

Conclusions: Suboptimal control, when it is present, prompts exploration of a wide range of factors. Assessment of family functioning should be part of this process, even if there is no evidence of major family difficulties because subtle distortions in functioning can significantly influence glycaemic control, especially in early adolescence.
\end{abstract}

Keywords: Diabetes, cohesion, adaptation, family functioning, FACES IV

\section{Background}

The management of diabetes in children is a challenging experience for any family. The issues of close dietary management, frequent testing and medication, and the ever present worry of life-threatening crisis if the regime fails, quite naturally places a major strain on family functioning. This is compounded by the recognition that maintaining optimal glycaemic control is a central element of diabetes care in order to prevent or delay complications associated with the condition [1]. Diabetes can also present a risk to the psychological well-being of both the child with diabetes and their family [2], and the majority of research indicates that young people with diabetes are at increased risk of mental health difficulties. Indeed it has been suggested that these varied and persistent threats may become the organising principle of family life in some families [3].

Adolescence is particularly problematic for families because the developmental demands of this phase can make the maintenance of optimal control difficult [4]. Indeed, research indicates that the majority of adolescents with type 1 diabetes tend not to achieve optimal levels of HbA1c [4], and in a recent audit in the UK only $14.5 \%$ of children and young people with a HbA1c measurement achieved the recommended target for optimal control [2]. When the diabetes arises in childhood the worry for families is increased further by the recognition that the duration of the illness tends to predict the degree of adherence and quality of glycaemic control, because the more prolonged the disease the lower the level of these elements [5].

Work seeking to understand the relationship between family resources and how they influence illness outcomes has highlighted the importance of the total family system [7] because when a family is faced with a child developing a potentially life-threatening condition it naturally prompts

(C) 2013 Place et al; licensee Herbert Publications Ltd. This is an Open Access article distributed under the terms of Creative Commons Attribution License (http://creativecommons.org/licenses/by/3.0). This permits unrestricted use, distribution, and reproduction in any medium, provided the original work is properly cited. 
Whitehead et al. Journal of Diabetes Research \& Clinical Metabolism 2013,

major changes in relationships and functioning. In the case of type 1 diabetes the potential for difficulties are a continuing concern and research in this area has persistently found that families who struggle with management have strained family functioning [6], with the potential for families to become too overprotective towards their child and too rigid in their management as they try to maintain the care regime their child's illness requires. It has been suggested that sometimes the illness may rule the family system and may result in the family forfeiting other developmental needs [3]. If this occurs then the family's ability to manage the illness effectively may be disadvantaged [8].

Given these strains and challenges it is therefore perhaps surprising that so many families manage to establish a settled and successful pattern of function. When exploring the mechanisms involved, perhaps two of the parameters which are most relevant in measuring the family's success are the degree of over involvement between family members (cohesion) and the amount of over control and rigidity that is imposed (flexibility). One of the many studies using the Family Adaptation Cohesion and Evaluation Scale to examine these parameters [9] found a link between high rigidity and suboptimal glycaemic control and that the quality of glycaemic control was positively correlated with mothers' perceptions of their family's ability to be flexible.

In most studies it has been the dimension of cohesion that has been most consistently found to be correlated with the quality of glycaemic control [10], as well as medication compliance [11]. However the degree of cohesion found still tends to be of a lesser degree than found in families with a healthy child. $[12,13]$. This is perhaps a consequence of the fact that much of the work in this area has been in families where problems were evident $[\mathbf{1 4}, \mathbf{1 5}]$, and it may be that more optimal functioning is associated with patterns of family dynamics that are more normative.

The aim of the present study was to explore whether suboptimal glycaemic control was associated with variations in family functioning that might not, in themselves, prompt concern in routine clinic review. The hypothesis driving the study was that quite modest variations in family functioning would be associated with suboptimal control, and the sample was specifically chosen to not include families that might have any complicating family or health factors, and where the index child was around the major transitional phase of puberty.

\section{Methods}

Having obtained ethical approval from academic and NHS bodies, families with a child between the age of 9 to 16 years who had a diagnosis of type 1 diabetes mellitus and were currently attending one of five specialist paediatric diabetes clinics in the North East of England were considered for inclusion. All clinic attenders within the age range were considered for inclusion and the clinical staff asked to exclude any where there was concern about the family's coping or day-to-day management, or it was known that there was a member with a serious illness, severe psychopathology (e.g. psychosis), or significant learning disability. In order to maximise efficiency in relation to participant recruitment, and have more distinct groups to compare, an experimental design was chosen in which participants were purposively recruited for the study based on the average level of their glycaemic control ( $\mathrm{HbA1C}$ value). For the purposes of the study the mean of the last four $\mathrm{HbA} 1 \mathrm{c}$ readings was calculated and optimal glycaemic control was taken to be $(\mathrm{HbA} 1 \mathrm{C}$ value $<7.5 \%$ or $<58 \mathrm{mmol} / \mathrm{mol}$ ), with suboptimal glycaemic control as ( $\mathrm{HbA} 1 \mathrm{C}$ value $>9 \%$ or $>75 \mathrm{mmol} / \mathrm{mol}$ ).

Data was gathered from participating families on issues such as the index child's age, other physical health issues, special educational requirements, as well as details about the onset of the diabetes, and the child's current care regime. Family structure was also explored, looking at issues such as family composition, physical health issues of family members, and any special educational requirements of other children within the family. The participating mothers and all the children over 12 years of age were asked to complete the Family Adaptation and Cohesion Evaluation Scales (FACES IV) [16]. This is a self-report measure comprising 62 statements; 42 of the items measure family cohesion and family flexibility. It is considered to be one of the better instruments to assess families on a system level, and has been chosen by various studies to examine the family issues in studies of children with diabetes $[12,14,15]$. Each scale represents a continuum of family functioning. The cohesion scale ranges from extremely low (disengaged) through moderate levels (separated, connected) to extremely high (enmeshed). Flexibility ranges from extremely low (rigidity) through moderate levels (structured, flexible) to extremely high (chaotic). The moderate levels are assumed to be more functional than the extreme levels on each scale. Flexibility is the ability to change structure, roles and relationships in response to situational and developmental stress, and cohesion is the degree of emotional attachment between family members [17].

Two scales measure the overall dimensions of family cohesion and family flexibility; with subscales measuring the degree to which the family is disengaged, enmeshment, rigid and chaotic. The first 52 statements included in the FACES IV are ranked on 5-point scale (Strongly Disagree, Generally Disagree, Undecided, Generally Agree, Strongly Agree), and the final 10 statements are ranked on an alternate 5-point scale (Very Dissatisfied, Somewhat Dissatisfied, Generally Satisfied, Very Satisfied, Extremely Satisfied). The scale was developed from the Circumplex Model, which is based on the hypothesis that for healthy family functioning balanced levels of cohesion and flexibility are optimum. Problematic family functioning is associated with unbalanced levels of cohesion (a score $<15$ being designated disengaged and $>85$ being enmeshed) and flexibility (a score of $<15$ being rigid and $>$ 85 being chaotic). Reliability of the FACES IV scales has been 
Whitehead et al. Journal of Diabetes Research \& Clinical Metabolism 2013, http://www.hoajonline.com/journals/pdf/2050-0866-2-16.pdf

Table 1. Descriptive Statistics of Participants in the Optimal and Suboptimal Control Groups.

\begin{tabular}{|c|c|c|c|c|c|c|c|c|}
\hline \multirow{3}{*}{$\begin{array}{l}\text { Child Participant } \\
\text { Information }\end{array}$} & \multicolumn{8}{|c|}{ Quality of Glycaemic Control } \\
\hline & \multicolumn{4}{|c|}{ Optimal $(n=25)$} & \multicolumn{4}{|c|}{ Suboptimal $(n=27)$} \\
\hline & Frequency (\%) & $M$ & $S D$ & Range & Frequency (\%) & $M$ & $S D$ & Range \\
\hline \multicolumn{9}{|l|}{ Gender } \\
\hline Male & 60.0 & - & - & - & 55.6 & - & - & - \\
\hline Female & 40.0 & - & - & - & 43.4 & - & - & - \\
\hline Age (Years) & - & 12.99 & 1.87 & $9.8-16.5$ & - & 13.32 & 1.95 & $10-16.6$ \\
\hline Duration of Diabetes (Years) & - & 5.51 & 2.85 & $2.1-14.9$ & - & 5.69 & 2.75 & $2.1-10.7$ \\
\hline Average HbAlc \% & - & 7.15 & 0.23 & $6.6-7.4$ & - & 10.16 & 1.04 & $9-13.5$ \\
\hline $\mathrm{Mmol} / \mathrm{mol}$ & - & 54.5 & 2.4 & $49-57$ & - & 87.5 & 11.4 & $75-124$ \\
\hline Insulin Delivery & - & - & - & - & - & - & - & - \\
\hline Pen & 76 & - & - & - & 62.9 & - & - & - \\
\hline Pump & 24 & - & - & - & 37.1 & - & - & - \\
\hline
\end{tabular}

found to be acceptable for research and clinical purposes with Cronbach's a values for the scales and subscales being; Cohesion $=0.89$, Flexibility $=0.84$, Rigid $=0.82$, Enmeshed $=$ 0.77 , Disengaged $=0.87$, and chaotic $=0.86[16]$ It has also been shown to discriminate between healthy and problematic family functioning [17].

'Predictive Analytics Software' was utilised in the statistical analysis of data. In terms of demographic information, independent samples t-tests were conducted to detect any significant differences between the optimal and suboptimal groups for the continuous variables, and Chi-Square analysis was undertaken to detect any significant differences between the groups for non-parametric data. Statistical analysis was then undertaken in order to investigate differences between the optimal and suboptimal groups for the scores on all the sub-scales of the FACES IV. t-tests were undertaken in order to investigate differences between child and maternal perceptions of family functioning, and assumptions for the t-test were confirmed [18]. In addition Pearson product moment correlations were also undertaken to assess the degree of linear dependence between sub-scores.

\section{Results}

Of the 66 families originally approached, two did not meet the inclusion criteria, and of the remaining 64 families 52 completed the data for this aspect of the study. Children attending the clinics who were 9 to 16 years of age were approached, with the mean age of participants being 13.2 yrs (Std Dev 1.9). $58 \%$ of the total sample were male, and $89 \%$ White British. The children had been diagnosed with type 1 diabetes for approx. 5.6 yrs at the time of the study (Std Dev 2.8 ); $76.9 \%$ were using a pen for insulin delivery, and $47 \%$ had optimal diabetes control using the criteria detailed by the National Institute of Clinical Excellence [19]. Table 1 details the results when considering the optimal and suboptimal control groups. Analysis showed there was no significant gender bias between the groups, the mean ages in both groups were similar, and the mean duration of diabetes was not statistically significant between the groups.

In considering the family make-up, $81.3 \%$ were two parent families, with $72 \%$ having more than one child. The sample had been chosen to be representative of the average clinic attenders, and those with known mental health or family difficulties were not approached. As the project information was being gathered no further exclusions were necessary. Comparing the pattern of family functioning with the FACES IV published norms, both the mothers and the children in the suboptimal control group had a wider spread scores than the optimal control families, but only in three families did the scores fall outside of the range of acceptable balanced family functioning, and in two of these there was optimal glycaemic control.

Table 2 shows the scores from the child sample, with the scores showing significant differences between the groups on specific parameters. There was a positive pattern of cohesion and flexibility in children whose glycaemic control was optimal, and there was a trend towards them reporting better family communication than those with suboptimal control. There was no difference in the degree of disengagement between family members, but children with suboptimal control viewed their families as more chaotic and reported less satisfaction with them. A Pearson product-moment correlation coefficient was undertaken upon the data and the only significant correlation was between the level of glycaemic control and the chaotic score $(r=.317, p=.019)$.

Table 3 shows the comparison of results when the mothers' responses were analysed. The mothers whose children showed optimal control reported their families to be more cohesive, and the Pearson product-moment correlation coefficient showed a significant association between cohesion and optimal glycaemic control $(r=.280, p=.026)$, the only significant association. It is also worth noting that the mothers in families with optimal glycaemic control did not report the flexibility that their children reported, rather they tended to 
Whitehead et al. Journal of Diabetes Research \& Clinical Metabolism 2013, http://www.hoajonline.com/journals/pdf/2050-0866-2-16.pdf

Table 2. Mean, Standard Deviation and t-test Values for the Child Sample on the FACES IV Subscales.

\begin{tabular}{lccccc}
\hline & \multicolumn{2}{c}{ Optimal $(\mathbf{n}=\mathbf{2 1})$} & \multicolumn{2}{c}{ Suboptimal $(\mathbf{n}=22)$} & \\
\cline { 2 - 6 } & $\boldsymbol{M}$ & $\boldsymbol{S D}$ & $\boldsymbol{M}$ & $\boldsymbol{S D}$ & $\begin{array}{c}\boldsymbol{t} \text {-test } \\
(\boldsymbol{d} \mathbf{f}=\mathbf{4 1})\end{array}$ \\
\hline Cohesion & 67.1 & 9.23 & 61.39 & 8.84 & $2.52^{\star}$ \\
Flexibility & 58 & 9.7 & 50.78 & 12.27 & $2.63^{*}$ \\
Disengaged & 32 & 9.34 & 31.87 & 11.62 & 0.05 \\
Enmeshed & 30 & 11.79 & 26 & 11.03 & 1.4 \\
Rigid & 42.75 & 21.31 & 41.13 & 19.24 & 0.32 \\
Chaotic & 25.35 & 13.15 & 35.3 & 16.76 & $-2.66^{\star *}$ \\
Communication & 56 & 23.22 & 47.04 & 21.8 & 1.59 \\
Satisfaction & 50.6 & 19.98 & 35.13 & 21.73 & $2.97^{* *}$ \\
\hline${ }^{*} \mathrm{p}<0.05,{ }^{* *} \mathrm{p}<0.01$. & & & &
\end{tabular}

Table 3. Mean, Standard Deviation and t-test Scores for the Maternal Sample on the FACES IV Subscales.

\begin{tabular}{|c|c|c|c|c|c|}
\hline & \multicolumn{2}{|c|}{ Optimal $(n=25)$} & \multicolumn{2}{|c|}{ Suboptimal $(n=27)$} & \multirow[b]{2}{*}{$\begin{array}{c}t \text {-test } \\
(d f=50)\end{array}$} \\
\hline & $M$ & $S D$ & $M$ & $S D$ & \\
\hline Cohesion & 66.76 & 13.58 & 60.33 & 13.31 & $1.72^{\star}$ \\
\hline Flexibility & 55.44 & 13.67 & 54.56 & 11.96 & 0.25 \\
\hline Disengaged & 20.20 & 4.55 & 23.41 & 11.67 & 1.29 \\
\hline Enmeshed & 17.52 & 4.51 & 17.78 & 4.97 & 0.20 \\
\hline Rigid & 37.40 & 14.16 & 34.81 & 16.68 & 0.60 \\
\hline Chaotic & 26.64 & 11.69 & 30.93 & 16.91 & 1.06 \\
\hline Communication & 71.72 & 14.41 & 57.59 & 22.04 & $2.71^{\star *}$ \\
\hline Satisfaction & 62.32 & 18.52 & 49.63 & 25.63 & $2.03^{\star}$ \\
\hline
\end{tabular}

feel a little more disengaged. They did however recognise having high levels of communication and reported a greater sense of satisfaction with family life than mothers in the suboptimal group.

\section{Discussion}

Sample selection had aimed to identify families that would be within the balanced range of the Circumplex Model, indicating that families are reasonably adjusted and functioning in an effective manner. Within this selected group, the mothers of children with optimal glycaemic control reported their family to be more cohesive and expressed greater satisfaction with family life than mothers whose child's glycaemic control was suboptimal. In the scales completed by the children, those with suboptimal control tended to view their family life as more chaotic.

Research into the functioning of families where a child has type 1 diabetes has often revealed major differences when glycaemic control is suboptimal. This has led to a suggestion that optimal control of diabetes is achieved in families who are more "controlling" [20], but this is a style of family life that cannot resist the developmental imperative of adolescent independence without prompting difficulty. Indeed, rather than being controlling, the parents of those with optimal diabetic control have usually been found to be promoting independence and self-expression in their children [6].

In general, research suggests that optimal control is found in individuals from families which are perceived to be organised, and where there is continued parental monitoring of the diabetes regimen during adolescence [21]. It has been suggested that such family functioning permits these individuals to internalise the organisation and structure observed within the family and that they are then able to apply this when managing their diabetes [22], a mechanism recognised in various other areas of functioning for instance morality [23].

The results of this study show that both the children with type I diabetes and their mothers have a greater sense of cohesion within family life if diabetic control is optimal. Previous research has identified cohesion as a significant variable influencing diabetic control, with most studies identifying marked cohesion as a main characteristic of families in optimal control of the child's diabetes [6,24]. Higher family cohesion is usually associated with parental warmth (defined as support and affection), and an "authoritative" style of parenting (which involves being engaged with the child with warmth while limit-setting and having high maturity demands with low levels of coercive control). These features also contribute to higher levels of adherence and cooperation by the child or adolescent with the tasks of diabetes treatment, and hence to better diabetic control [25]. The converse, that adolescents with suboptimal diabetic control tend to view their families as less competent and less cohesive, has also been a frequent finding [26].

In this study the children in the optimal control group viewed the family as significantly more flexible but their mothers did not, indeed they tended to report feeling more disengaged than the mothers in the suboptimal group. This highlights the differing perceptions that might be expected from family members as a child progresses through adolescent transition because it is well recognised that adolescents perceptions of family functioning frequently differ from those of their parents [26]. However this divergence is occurring at a time when there is often a shift in responsibility for the management of the diabetes, with the adolescent assuming more responsibility [27]. Such a transfer requires significant changes to roles and responsibilities within the family, with a lessening of previous involvement in the adolescent's dayto-day activities, and might go some way to explain why the mothers in the optimal control group reported feeling more disengaged.

Mothers, and to a lesser degree their children, reported in the current study that there was a better level of communication when diabetic control was optimal, and both indicated there was a higher degree of satisfaction with family life than for 
those in the suboptimal group. To achieve optimal control diet and treatment regimes need to be complied with, and in turn achieving optimal control is likely to give a settled feel to this aspect of family life. Indeed this study found that when control was suboptimal the children reported a significantly chaotic feel to family life. The characteristics of this parameter include lack of leadership, dramatic role shifts, erratic discipline and a sense of there being too much change. These could clearly arise when there are difficulties in establishing a settled regime, and also in turn could potentially increase the degree of challenge the family faced in trying to achieve this.

\section{Study limitations}

There are several limitations to the study that should be born in mind. The family information was generated from self-report questionnaires which have inherent potential to bias, though the FACES IV has been shown to be reasonably accurate at reflecting individuals' perceptions of family functioning, albeit in an American population [16]. Also it is recognised that because there is a descriptive quality to some of the questions this may make the scale sensitive to a wide range of influences in smaller samples e.g. unemployment, the percentage of single parents. However analysis of the demographic parameters of the two groups in this study did not show any significant differences between them on such factors so they are unlikely to distort the comparative findings. Of course a cross-sectional design does not permit inference about causation to be made, while the relatively small sample size, and the selective nature of subject inclusion, means generalising the results to the wider population must be done with great caution.

\section{Helping families towards better management}

It is perhaps not surprising that optimal diabetic control gives a sense of satisfaction and a sense of family cohesion. When treatment regimes are going well intervention is unnecessary. However research work has shown that if control is not optimal parents tend to report that the diabetes has negatively affected the child's functioning in areas such as their personality, physical well-being, schooling, and participation in activities away from home [5]. In the present study, although not a presenting concern, suboptimal control often indicated that family dynamics were somewhat unsettled. If this is the case then some evaluation of the functioning and provision of sessional input focused upon this may be very helpful in moving the family towards a better level of diabetic control.

\section{The impact of adolescence}

The associations identified in current and previous research between family cohesion, disease management and diabetic control illustrate the protective nature of a positive family environment in relation to achieving the most favourable health outcomes [24]. As children mature they need to accept increasing responsibility for the management of their diabetes, but when families feel able to surrender responsibility to the young person this transfer of responsibility is often not undertaken in a planned way [28]. This is also a time when wider changes in functioning are occurring, making it a period of life which is challenging for any youngster, but particularly so for individuals with type 1 diabetes [3]. Of clear concern is the fact that during adolescence diabetic control tends to decline, possibly as a result of the decreased involvement from parents [29], giving further stress to this transitional process. The early research in this area [30] suggested that an overrigid family organisation was associated with suboptimal control, and this has tended to be a consistent finding in subsequent research. This was not evident in the present study, and prompts a tentative speculation that perhaps rigidity in family functioning tends to prompt a greater level of difficulty with diabetic control than was explored here. Finding the balance in this area is important because fostering the sense of independence and self-expression that is a task of adolescence must be combined with giving the sense of containment and boundary that adolescents require [21].

\section{Practice implications}

The monitoring of the psychological health of children is increasingly recognised as an important element of care, however focussing upon the wider family functioning is not often stressed. Offering assistance in these circumstances tends to require a family-focussed approach which may not be easily accessible in routine follow-up clinics. Such an approach relies upon the concept that difficulties do not arise within the individual but in the relationships, interactions and language that develop between individuals, with an aim of helping reduce issues of blame as well as promoting a more open way of communicating. The family therapy approach recognises that patterns of behaviour that develop within families are repetitive and circular in nature, and are constantly evolving. An individual family member's behaviour affects other family members, which in turn affects the individual [31], and so everyone's behaviour impacts upon everyone else. Understanding the central themes in a family's life story is a powerful style of intervention, with the emphasis upon understanding the way people view themselves, their family, and the environment in which they live. One of the aims of such intervention can be to invite the family or individual to detach themselves from the problem and to see it as a story that exists outside themselves. In this way, the impact of "diabetes" on family members and the family system as a whole can be explored. Other issues arising such as "arguments" or "worry" can also be externalised and the family can think together about what resources they have to combat these difficulties. This can help parents/carers to consider that "the problem is the problem" rather than "the child is the problem" [32].

It has been suggested that such family approaches may 
be most effective during early to mid-adolescence, helping the child to effectively progress through this developmental stage, with a more individual approach being adopted in late adolescence [13], but this may be to deprive older adolescents of the opportunity to address wider family concerns. However intervention strategies must work within the existing family system, respecting the parental involvement in the diabetes management tasks, and sometimes shifting the question from "how much involvement?" to "how is this involvement communicated?" When the warmth, limit-setting, and encouragement of appropriately authoritative parents are brought to bear on interactions around diabetes management, youth of all ages may experience this involvement as more supportive and less stressful and, in turn, feel better about themselves and about their parent.

\section{Conclusions}

Managing diabetes is a challenge for any family, and while most families cope reasonably well, less than optimal diabetes control may indicate the presence of some family issues, the correction of which is likely to improve overall diabetes control and the quality of family life more generally. These issues may not initially be evident because of their subtle nature, but especially in early adolescence even minor frictions can have significant impact upon maintaining routines and complying with treatment regimes.

\section{Competing interests}

The authors declare that they have no competing interests.

\section{Authors' contributions}

AW was collaborator in the design the project, carried out the field work, and participated in data analysis and writing this paper. MD participated in data analysis and writing this paper.

MP was collaborator in the design the project and participated in data analysis and writing this paper.

\section{Acknowledgement}

Our grateful thanks to the staff of the paediatric departments of the North East Diabetes Forum for their untiring cooperation and assistance.

\section{Publication history}

Received: 20-Dec-2012 Revised: 29-Jan-2013

Re-Revised: 16-Feb-2013 Accepted: 18-Mar-2013

Published: 22-Mar-2013

\section{Reference}

1. American Diabetic Association: National Diabetes Fact Sheet. 2011. | Website

2. Healthcare Quality Improvement Partnership: National Diabetes Paediatric Audit Report 2009-2010. 2011. I Pdf

3. Cohen MW: Families coping with childhood chronic illness: A research review. Fam Syst Health 1999, 17: 149-64. I Article

4. Ingerski LM, Anderson BJ, Dolan LM and Hood KK: Blood glucose monitoring and glycemic control in adolescence: contribution of diabetes-specific responsibility and family conflict. J Adolesc Health 2010, 47:191-7. | Article | PubMed Abstract | PubMed Full Text

5. Donnelly LA, Morris AD and Evans JM: Adherence to insulin and its association with glycemic control in patients with type 2 diabetes. $Q \mathrm{~J}$
Med 2007, 100: 345-50. I Article

6. Anderson BJ, Miller JP, Auslander WF and Santiago JV: Family characteristics of diabetic adolescents: relationship to metabolic control. Diabetes Care 1981, 4:586-94. | Article | PubMed

7. Nansel TR and Hood KK: Diabetes in Childhood: Promoting Emotional Health. In Gullotta T \& Blau G (Eds.), Handbook of Child Behavioral Issues: Evidence-Based Approaches. 2007, 251-4.

8. Lavigne JV and Faier-Routman J: Correlates of psychological adjustment to pediatric physical disorders: a meta-analytic review and comparison with existing models. J Dev Behav Pediatr 1993, 14:117-23. I Article I PubMed

9. Cederblad M, Helgesson M, Larsson $Y$ and Ludvigsson J: Family structure and diabetes in children. Pediatr Adolesc Endocrin 1982, 10: 94-8.

10. Meunier J, Dorchy $\mathrm{H}$ and Luminet $\mathrm{O}$ : Does family cohesiveness and parental alexithymia predict glycaemic control in children and adolescents with diabetes? Diabetes Metab 2008, 34:473-81. | Article | PubMed

11. Kouneski EF: The Family Circumplex Model, FACES II, and FACES III: Overview of Research And Applications. University of Minnesota: Department of Family Social Science, 2003.

12. Hanson CL, Henggeler SW, Harris MA, Burghen GA and Moore M: Family system variables and the health status of adolescents with insulindependent diabetes mellitus. Health Psychol 1989, 8:239-53. | Article | PubMed

13. Seiffge-Krenke I: Psychological adjustment of adolescents with diabetes: Functional or dysfunctional for metabolic control? J Pediatr Psychol 1998, 23: 313-22. | Article

14. Cohen DM, Lumley MA, Naar-King S, Partridge T and Cakan N: Child behavior problems and family functioning as predictors of adherence and glycemic control in economically disadvantaged children with type 1 diabetes: a prospective study. J Pediatr Psychol 2004, 29:171-84. | Article I PubMed

15. Hanson CL, Cigrang JA, Harris MA, Carle DL, Relyea G and Burghen GA: Coping styles in youths with insulin-dependent diabetes mellitus. J Consult Clin Psychol 1989, 57:644-51. I Article I PubMed

16. Olson D: FACES IV and the Circumplex Model: validation study. J Marital Fam Ther 2011, 37:64-80. I Article I PubMed

17. Olson DH and Gorall DM: Circumplex Model of Marital and Family Systems. In: Walsh F. (Ed), Normal Family Processes. 3rd edn. 2003, 514-47. I Book

18. Clark-Carter D: Quantitative Psychological Research. 2010, 197-8. | Book

19. 1National Institute of Clinical Excellence: Type 1 diabetes: Diagnosis and management of type 1 diabetes in children, young people and adults: Clinical Guideline 15. 2004. I Website

20. Weist MD, Finney JW, Barnard MU, Davis CD and Ollendick TH: Empirical selection of psychosocial treatment targets for children and dolescents with diabetes. J Pediatr Psychol 1993, 18:11-28. I Article I PubMed

21. Luyckx K and Seiffge-Krenke I: Continuity and change in glycemic control trajectories from adolescence to emerging adulthood: relationships with family climate and self-concept in type 1 diabetes. Diabetes Care 2009, 32:797-801. I Article I PubMed Abstract I PubMed Full Text

22. Williams GC, Freedman ZR and Deci EL: Supporting autonomy to motivate patients with diabetes for glucose control. Diabetes Care 1998, 21:1644-51. | Article | PubMed

23. Hardy SA, Bhattacharjee A, Reed li A and Aquino K: Moral identity and psychological distance: the case of adolescent parental socialization. $J$ Adolesc 2010, 33:111-23. | Article I PubMed

24. Mackey ER, Hilliard ME, Berger SS, Streisand R, Chen R and Holmes $\mathrm{C}$ : Individual and family strengths: an examination of the relation to disease management and metabolic control in youth with type 1 diabetes. Fam Syst Health 2011, 29:314-26. | Article | PubMed

25. Anderson BJ: Family conflict and diabetes management in youth: Clinical lessons from child development and diabetes research. Diabetes Spectr 2004, 17: 22-6. I Article I Pdf

26. Zashikhina A and Hagglof B: Family functioning and juvenile chronic physical illness in Northern Russia. Acta Paediatr 2009, 98:355-60. | 
Whitehead et al. Journal of Diabetes Research \& Clinical Metabolism 2013, http://www.hoajonline.com/journals/pdf/2050-0866-2-16.pdf

Article I PubMed

27. Miller VA and Drotar D: Discrepancies between mother and adolescent perceptions of diabetes-related decision-making autonomy and their relationship to diabetes-related conflict and adherence to treatment. J Pediatr Psychol 2003, 28:265-74. | Article | PubMed

28. Anderson BJ, Auslander WF, Jung KC, Miller JP and Santiago JV: Assessing family sharing of diabetes responsibilities. J Pediatr Psychol 1990, 15:477-92. | Article | PubMed

29. Guo J, Dixon JK, Whittemore R and He GP: Instrument translation and initial psychometric evaluation of the Chinese version of the SelfManagement of Type 1 Diabetes for Adolescents scale. J Adv Nurs 2013, 69:960-969. | Article | PubMed

30. Minuchin S, Baker L, Rosman BL, Liebman R, Milman L and Todd TC: A conceptual model of psychosomatic illness in children. Family organization and family therapy. Arch Gen Psychiatry 1975, 32:1031-8. | Article | PubMed

31. Jacobson AM: The psychological care of patients with insulindependent diabetes mellitus. N Engl J Med 1996, 334:1249-53. | Article I PubMed

32. Epston D and White M: Narrative Means to Therapeutic Ends. New York: Norton 1990. I Article

\section{Citation:}

Whitehead A L, Dimmock M and Place M: Diabetes control and the influence of family functioning. Journal of Diabetes Research and Clinical Metabolism 2013, 2:16. http://dx.doi.org/10.7243/2050-0866-2-16 